\title{
VILLANCICOS DE TERESA, VILLANCICOS PARA TERESA. DE 1562 A $1661^{1}$
}

\author{
ESTHER BORREGO GUTIÉRREZ \\ Universidad Complutense de Madrid \\ eborrego@ucm.es
}

Yo sé persona, que con no ser poeta, le acaescía hacer de presto coplas muy sentidas.

(Libro de la Vida, 16)

Para Ana Martínez Muñoz

$\mathrm{E}$ $\mathrm{s}$ de justicia reconocer el esmerado trabajo editorial que demuestran las sucesivas publicaciones del corpus poético teresiano, afrontado esencialmente desde el siglo xx, pero se echa en falta una edición actualizada de tipo filológico y crítico. Como es sabido, abundan los poemas de la santa difundidos en editoriales religiosas o divulgativas, cuyas particularidades y finalidad distan mucho, lógicamente, de los criterios de rigor ecdótico exigibles a un material literario de sumo interés ${ }^{2}$. En esta línea, y respecto a la forma poética objeto de este

1 Este artículo nace de un trabajo comenzado en 2014, a raíz de la invitación del profesor Ignacio Arellano a participar en el Congreso «Santa Teresa y la cultura religiosa de su tiempo», celebrado en la Universidad Popular del Estado de Puebla (México) entre el 28 y el 30 de octubre de 2015. Por motivos ajenos a mi voluntad no pude publicar en su momento el resultado de esa investigación, que ahora se ve ampliada y mejorada. Asimismo, este trabajo se ha podido realizar gracias al Proyecto de investigación UCM-Santander: «Literatura en el claustro. Poesía, teatro y otros géneros (híbridos) en un convento de fundación real de la Edad Moderna: las Descalzas Reales de Madrid» (26/16-20298) y del Grupo de Investigación UCM, «Hibridismo literario y cultura áurea» (970841). En ambos soy la investigadora principal.

2 Por este motivo hemos excluido de la bibliografía las antologías divulgativas, las recopilaciones de poemas que apenas incluyen un mínimo prólogo o introducción, y, por supuesto, las innumerables páginas web que acogen poemas teresianos - la mayoría sin indicación crítica alguna-, especialmente difundidas y visitadas a partir de 2015 con motivo del V Centenario del

Edad de Oro, XXXVII (2018), pp. 45-74, ISSN: 0212-0429 - ISSNe: 2605-3314

DOI http://dx.doi.org/10.15366/edadoro2018.37.002 
trabajo, el villancico, ya hace más de cuarenta años que el padre Ángel Custodio Vega exhortaba a la elaboración de un estudio y de una edición «crítica y esmerada» de estas piezas teresianas:

[...] la Santa dedica bastantes de sus composiciones al villancico, género poético característico, al que supo inspirarle toda la ternura de su corazón. Distínguense los de nuestra Santa por su extremada sencillez y claridad, por su devoción y gracia y por su sabor y estilo popular. A veces parecen descuidados su lenguaje y su versificación. Pero hay que tener presente que no poseemos aún una edición crítica y esmerada ${ }^{3}$ y que este género de poesía era el más expuesto a corrupciones y alteraciones por las manos que corría (Vega 1972: 42).

Por desgracia, los villancicos apenas han merecido la atención de la crítica, aunque hay que reconocer que esta desatención se contextualiza en la que ha recibido la «otra» poesía de Santa Teresa. Así, aunque es casi un lugar común la gran facilidad que tenía la santa para versificar, su reconocimiento como poeta no alcanzaría al que se le rindió como prosista; no fue así por parte del canon, desde luego, pero tampoco mereció en general el aplauso de la crítica académica. Por otra parte, es difícil determinar el número exacto de los poemas de atribución segura a Santa Teresa de Jesús, pues según la edición de la BAC (2013), que es la que hemos seguido en la transcripción de los textos, estos serían veintisiete, pero no todas las ediciones coinciden en ese número ${ }^{4}$. En todo caso, se advierte en la composición y conservación de los poemas una gran despreocupación por su transmisión textual; de hecho, en los siglos XVI y XVII circularon desorganizadamente $\mathrm{y}$, sobre todo, de manera oral por los conventos de carmelitas y por

nacimiento de Santa Teresa. En todo caso, se puede comprobar que las más relevantes ediciones de los poemas teresianos se albergan en varios casos en colecciones más cercanas a la espiritualidad que al estudio filológico.

3 La cursiva es mía.

4 El primer editor de las poesías, Vicente de la Fuente (Santa Teresa 1861: 507), daba por ciertas siete; por «probablemente suyas», trece; y por dudosas, veintiuna. El padre Silverio (Santa Teresa 1922) no cuestiona nada sobre la autenticidad de los poemas y se limita a editar siete. En Santa Teresa (1972), el padre Vega fija en veintiocho el número de piezas auténticas y en cuatro las que él llama «apócrifas», criterio que se sigue en Santa Teresa (1977), aunque se cambia una de las apócrifas por otra; los editores, Barrientos y Rodríguez, dan por seguras veintiocho y cuatro por apócrifas, afirmando, en cuanto al discernimiento de la autoría, que «algunas tienen historia propia, transmitida por testigos o por historiadores; otras, la mayoría, se historian ellas mismas por su claro contenido interno» (17). En Santa Teresa (1994), el padre Llamas determina la autenticidad de veintinueve y tiene tres por dudosas. Finalmente, Herráez (Santa Teresa 1997: 1104), tras esbozar la dificultad de «establecer con seguridad la filiación teresiana de algunas poesías», lo que para él «no es grave», procede a editar sin más treinta y tres poemas. Como se deduce de la reunión de estas opiniones, urge un estudio riguroso y científico que logre esclarecer la autenticidad de la poesía teresiana. 
ambientes cercanos a ellos. Sorprende que fuera cerca de dos siglos después de la muerte de la santa, ya en el siglo XVIII, cuando consta la primera copia con interés archivístico $^{5}$, y que hasta bien entrado el siglo XIX no aparezca editado el corpus de sus poemas, concretamente en el tomo 53 de la $\mathrm{BAE}^{6}$ (1861). En el siglo Xx estas piezas poéticas sí figuran en ediciones de obras completas de Santa Teresa (1922, 1954, 1963, 1997), algunas reeditadas en el siglo XXI (Santa Teresa 2000, 2013), y en monográficos sobre su poesía (Vega 1972) o sobre poesía mística suya y de San Juan de la Cruz (Barrientos y Rodríguez 1977).

En cuanto a sus villancicos, no se incluyen en todas las compilaciones de poesía: por ejemplo, en Santa Teresa (1922) se prescinde por completo de ellos ${ }^{7}$, mientras que parece que hay unanimidad en cuanto a la determinación de los poemas que reúnen las condiciones para ser un «villancico»: en Santa Teresa (1861) se determinan siete, criterio que seguirán Vega (1972), Barrientos y Rodríguez (1977) y Efrén de la Madre de Dios y Steggink (2013). Herráez (Santa Teresa 1997) incluirá los siete villancicos tradicionales sin ninguna distinción específica, mientras que Llamas (Santa Teresa 2000) los integra en el apartado "poesías festivas y hagiográficas», prescindiendo de la denominación «villancico».

Esto enlaza con la taxonomía de la poesía teresiana, otro cajón de sastre, pues cada cual sigue sus criterios. Así, de la Fuente (1861) apenas esboza una vaga clasificación en la que distingue el «género lírico y erótico» del «género bucólico» (1861: 502) —en el que integra claramente los villancicos—, y añade otro apartado: el de las «canciones compuestas en las tomas de hábito» (1861: 503-504), dejando sin incluir en ningún apartado otros poemas que edita sin más explicación. El padre Silverio de Santa Teresa (1922) no procede a ningún tipo de organización y apenas dedica unas líneas generales a comentar los siete poemas que edita. El padre Vega (1972: 38), aun admitiendo que su clasificación podría «ampliarse o restringirse», distingue entre poesías: a) lírico-místicas; b) didáctico-ascéticas; c) letrillas de devoción; d) letrillas de circunstancias u ocasionales; y e) villancicos. Barrientos y Rodríguez (1977: 25, 40 y 53) distinguen «poesías lírico-místicas», «poesías festivas y hagiográficas» — categoría en la que incluyen los villancicos-y «poesías didácticas y de la vida religiosa». Herráez (1997) prescinde de

5 Los padres Andrés de la Encarnación y Francisco de Santa María, en torno a 1759, recopilaron todos los poemas guardados en varios monasterios de carmelitas, sobre todo en los de Toledo, Cuerva, Madrid y Guadalajara. Gracias a su labor, tras el expolio del Archivo General de los Carmelitas Descalzos, todo este material fue a parar a la Biblioteca Nacional de España. Ahí los encontró Vicente de la Fuente y los dio a conocer en el citado tomo 53 de la Biblioteca de Autores Españoles. Los manuscritos tienen las siguientes signaturas: mss. 1400, 5492, 12763 y 12764.

6 Véase Santa Teresa (1861). Hubo reimpresiones en 1877 y 1879

7 En las ediciones sucesivas $(1930,1939$ y 1954) se siguen recogiendo esos siete poemas y ningún villancico. 
clasificar los poemas. Llamas (Santa Teresa 2000) distingue entre «poesías lírico-místicas», «poesías festivas y hagiográficas» y «poesías didácticas y de vida religiosa», y no da lugar específico a los villancicos. Finalmente, Efrén de la Madre de Dios y Steggink (Santa Teresa 2013: 653), simplifican la clasificación dejando bien clara la categoría del villancico: «Las distribuimos por temas: Líricas (1-8), Villancicos (9-15), Votivas y familiares (16-27)», determinando que son siete las piezas que pueden adscribirse a este género, con lo que estamos de acuerdo. Esta especificidad del villancico fue percibida muy claramente por Santa Teresa, como género asociado a lo jocoso y a lo festivo, y en su caso, a lo popular, como podemos comprobar en dos cartas, una a su hermano Lorenzo y otra al convento sevillano, en la que pide a las monjas el acostumbrado villancico:

No sé qué le envié... si no es esos villancicos que hice yo, que me mandó el confesor las regucijase, y he estado estas noches con ellas y no supe cómo siendo así. Tienen graciosa sonada, si la atinare Francisquito para cantar [...] estos [villancicos] no tienen ni pies ni cabeza (Carta 168, 23, 36, del 2 de enero de 1577, en Santa Teresa 2013: 1065-1066).

He mirado cómo no me envían ningún villancico, que a usadas no habrá pocos a la elección, que yo amiga soy [de] que se alegren en su casa con moderación (Carta 315, 14, del 1 de febrero de 1580, en Santa Teresa 2013: 1257).

Este gusto por lo popular y por la espontaneidad en la composición, marca de los escasos villancicos que se han conservado, es apuntado por la carmelita María de San José, en el siglo María de Salazar, una de las primeras y predilectas discípulas de la santa: «Todo se pasaba riendo y componiendo romances y coplas de todos los sucesos que nos acontecían, de que nuestra Santa Madre gustaba extrañamente, y nos daba mil gracias porque con tanto gusto y contento pasábamos tantos trabajos» (María de San José 1585: XLI).

Pero es el padre Ribera el que añade a su condición de compositora de «coplas» y su modo de ejecutarlas, una nota específica sobre los villancicos:

Gustaba la Madre de que sus monjas anduvieran alegres y que cantasen en las fiestas de los santos e hiciesen coplas. Mas como gustaba de dar ejemplo en todo, hacíalas ella misma y las cantaba en unión de sus monjas, sin instrumento ninguno de música sino acompañándose con la mano, dando ligeras y suaves palmadas, para llevar compás y hacer cierta armoniosa cadencia. Pero aun los mismos villancicos rebosaban de amor divino (Ribera 1590: I. 4, c. 24).

Los juicios sobre sus villancicos han sido dispares: desde quien los consideró, en su primer viaje editorial, «tan estrafalarios, los conceptos tan bajos, las palabras tan toscas, que propiamente no son más que "coplas de papel de ciego", que en nada se parecen a las otras composiciones de Santa Teresa» (Santa Teresa 
1861: 503$)^{8}$, hasta la alabanza del padre Ángel Custodio Vega a alguno concreto, calificándolo de «pequeña joya literaria, un juguete poético con verdadero alarde de gracia, ingenio y devoción» (Vega 1972: 143). En el resto de ediciones apenas hay referencias a los villancicos ni valoraciones sobre ellos.

En el último tercio del siglo Xvi todavía se mantenía el sentido etimológico del término «villancico» (canciones de pueblo, de villanos, populares, de temática profana y religiosa), y el formal, pues se trataba de un género sujeto a una estructura métrica concreta ${ }^{9}$, que se «fijó» de forma regular en el Cancionero general de 1511. Así lo afirma el padre Vega, que opina que «este género literario tenía ya un estilo y lenguaje establecido, al que se adaptaban los poetas más encumbrados y cultos» (Vega 1972: 42). Fue el villancico en el siglo xvi la forma más abundante de la canción lírica y Santa Teresa no fue una excepción, aunque sea escaso el número de los conservados. De los siete villancicos teresianos considerados auténticos hasta el momento, cuatro son de Navidad, dos de Circuncisión y uno de Reyes. Aunque, como es sabido, el villancico en su origen no estaba asociado a las fiestas navideñas ni siquiera a asuntos religiosos, los cantares y coplas al Niño nacido en Belén se comenzaron a llamar «villancicos» precisamente por la presencia de pastores y gentes del pueblo en ellos, llegándose a crear una forma de la que era difícil salirse; y en esa forma escribió Santa Teresa los suyos. Es de destacar el elemento pastoril que todos los villancicos teresianos poseen y que se mantendrá en la evolución del género, pero además deseo destacar la presencia constante de un componente dialógico que será muy significativo a medida que avanzan las décadas, pues dará lugar a villancicos verdaderamente cercanos a lo teatral en el siglo XVII ${ }^{10}$.

En este sentido, si atendemos a los villancicos de Navidad, en ; Ah, pastores que veláis!11, se recomienda a los pastores, en concreto a Gil y a Sonzas, que actúa

8 La cita sigue: «Quizá las cantara con sus monjas la misma Santa por ser vulgares en su país, y de ahí que las copiaren como suyas». Vicente de la Fuente se atreve incluso a cuestionar la autoría de Santa Teresa en los villancicos, sin más fundamento que su intuición: «Algunos de ellos me inspiran sospechas acerca de su legitimidad. Creo que más bien serían villancicos cantados por las monjas, que no escritos por Santa Teresa» (Santa Teresa 1861: 503).

9 El villancico consta de un número indefinido de versos de arte menor, estructurados en cabeza, mudanza y versos de enlace, con predominio del octosílabo y en menor medida del hexasílabo.

10 Para la evolución del género, véase el espléndido estudio de Eva Llergo (2017). Asimismo, véase el reciente volumen sobre el villancico como género literario y musical (Borrego y Marín 2018).

11 Este título procede del primer verso del villancico. Así procederé con todos, citándolos por su primer verso. En las ediciones que hemos manejado se actúa de diversas formas para la titulación de los villancicos, asunto en el que no entro ahora pero sin duda interesante desde el punto de vista crítico. Para transcribir los textos de los villancicos, he tomado como base la edición de la BAC (Santa Teresa 2013), permitiéndome leves cambios en la puntuación y en alguna transcripción puntual. He utilizado la cursiva para los versos repetidos o similares del estribillo, subrayando así la vertiente musical del villancico. 
de simple, que guarden al cordero porque el lobo le acecha, con el claro doble sentido, el divino y el humano, este referido a su oficio. Ellos son verdaderos interlocutores: uno pide el cayado al otro para proteger al Niño; se confiesan mutuamente su aturdimiento y tristeza por la muerte del cordero-Jesús. En resumen, no se trata de una mera exposición poética a dos voces, sino que existe una clara interactuación, reflejada en algunos pasajes:

- Gil, dame acá aquel cayado, que no me saldrá de mano, no nos lleven al Cordero, ¿no ves que es Dios soberano?

— iSonzas!, que estoy aturdido de gozo y de penas junto, si es Dios el que hoy ha nacido, ¿cómo puede ser difunto? $¡ O h$, que es hombre tan bien junto, la vida estará en su mano!, mirad que éste es el Cordero, hijo de Dios soberano.

-Mía fe ${ }^{12}$, Gil, mijor será que se nos torne a su tierra, si el pecado nos destierra y está el bien todo en su mano. Ya que ha venido, padezca este Dios tan soberano.

Continuando en la línea de los diálogos de pastores, en Hoy nos viene a redi$m i r^{13}$ se adjudica directamente el papel de simple a uno de los pastores, Gil, por contraste con el «listo», Llorente, que le responde. Esta dualidad de personajes ya estaba presente en los primitivos autos religiosos, y pervivieron en el villancico barroco y en diversas formas teatrales áureas, sobre todo en las de índole cómica ${ }^{14}$; nótese la agilidad del diálogo y el alegre contrapunto de preguntas y respuestas:

12 Entiendo esta expresión como parecida a 'A la fe': «Modo adverbial, que vale verdaderamente, ciertamente, y las más veces con algún género de admiración o extrañeza. Es usado de los aldeanos y gente rústica» (Autoridades).

13 Sigo citando los villancicos por el primer verso, aunque este es denominado Nace el Redentor en Santa Teresa (2013: 659).

14 El contraste entre el pastor listo y el pastor tonto está presente desde el teatro de Juan del Encina; serán figuras que contribuirán remotamente a la formación del personaje del gracioso del teatro áureo español. 
- Hoy nos viene a redimir un zagal, nuestro pariente, Gil, que es Dios omnipotente.

— ¿Por eso nos ha sacado de prisión a Satanás?

-Mas es pariente de Bras y de Menga y de Llorente.

¡Oh, que es Dios omnipotente!

—Pues si es Dios, ¿cómo es vencido y muere crucificado?

— ¿No ves que mató el pecado padeciendo el inocente?

Gil, que es Dios omnipotente.

- Mía fe, yo lo vi nacido y una muy linda zagala.

Pues si es Dios, ¿cómo ha querido estar con tan pobre gente? — ¿No ves que es omnipotente?

—Déjate desas preguntas, miremos por le servir, y pues Él viene a morir, muramos con él, Llorente, pues es Dios omnipotente.

El siguiente villancico, Pues que el amor, ostenta un tono más lírico, de compasión ante el sufrimiento del Niño Dios a causa de las premoniciones de la Pasión, aunque la inserción de unos zagales concretos, Llorente y Pascual, mantienen el contexto pastoril de los villancicos anteriores. Tras la diseminación de elementos alusivos a la pobreza y al dolor («pobre cortijo», «frío», «sayal», «azotes», «ser muerto / de una mala gente») el poema no se escapa al vivo diálogo de los zagales:

Danos el Padre a su único hijo: hoy viene al mundo en pobre cortijo. ¡Oh, gran regocijo, que ya el hombre es Dios!

No hay que temer:

muramos los dos. 
Mira, Llorente, qué fuerte amorío; viene el inocente a padecer frío. Deja un señorío, en fin, como Dios. Ya no hay qué temer, muramos los dos.

¿Pues cómo, Pascual, hizo esa franqueza, que toma un sayal dejando riqueza?

Mas quiere pobreza, sigámosle nos, pues ya viene hombre, muramos los dos. ¿Pues qué le darán por esta grandeza? Grandes azotes con mucha crüeza. ¡Oh, qué gran tristeza será para nos!

Si esto es verdad, muramos los dos.

¿Pues cómo se atreven siendo omnipotente? Él ha de ser muerto de una mala gente. Pues si eso es, Llorente, hurtémosle nos.

¿No ves que él lo quiere?

Muramos los dos.

Un poema enteramente dialógico es Mi gallejo, mira quién llama, en el que un pastor cuenta a otro prácticamente in actu su asombro ante el nacimiento y ante la presencia de los ángeles con su cantilena («cantillana»), que le han alterado con un gran «zumbido» por el volumen de sus cantos. El villancico prescinde de los elementos trágicos de los anteriores y no falta en sus versos el humor, con la alusión a personajes de índole teatral cuya raíz es el «simple» o tonto, como el alcalde y el pastor, este último, seguramente gallego: 
—Mi gallejo ${ }^{15}$, mira quién llama.

-Ángeles son, que ya viene el alba.

- Hame dado un gran zumbido que parece cantillana.

- Mira Bras, que ya es de día, vamos a ver la zagala.

-Mi gallejo, mira quién llama.

-Ángeles son, que ya viene el alba.

—Es pariente del alcalde

u quién es esta doncella?

-Ella es hija de Dios Padre,

relumbra como una estrella.

-Mi gallejo, mira quién llama.

-Ángeles son, que ya viene el alba.

El único villancico de la santa dedicado a los Reyes presenta un notable interés, pues ya tipifica en cierto modo los motivos que serán fijos en la evolución de este tipo específico de piezas, destinadas a la fiesta litúrgica de la Epifanía: 1) la estrella; 2) el cumplimiento de las profecías con la llegada de los Magos a Belén; 3 ) el ofrecimiento de los pastores de sus animales, que se mezclarán con los animales «exóticos» que vienen de Oriente; y 4) los dones que llevan al Niño, entre los que despunta el más valioso: su corazón ${ }^{\mathbf{1 6}}$. Nótese cómo se introduce levemente la segunda persona, con la figura del pastor Llorente, en un villancico que apenas presenta forma dialógica, a diferencia de los anteriores:
Pues que la estrella
es ya llegada,
va con los Reyes
la mi manada.
Vamos todos juntos
a ver al Mesías,

\footnotetext{
15 Vega (1972: 146) confiesa su dificultad para la transcripción de estas palabras: «no sé si se debe escribir "Mi gallejo", como hacen casi todas las ediciones, o bien "Migallejo", que sería abreviatura de "Miguel" o "Miguelejo"». Finalmente, opta por esta última palabra pero nosotros estamos más de acuerdo con la edición de la BAC (Santa Teresa 2013: 660), en la que entienden «Mi gallejo» por «Mi gallego».

16 Vega (1972: 158) hace notar la inspiración enciniana de este villancico.
} 
que vemos cumplidas

ya las profecías.

Pues en nuestros días

nos es ya llegada,

va con los Reyes

la mi manada.

Llevémosle dones

de grande valor,

pues vienen los Reyes

con tan gran hervor.

Alégrese hoy

nuestra gran zagala,

va con los Reyes

la mi manada.

No cures, Llorente, de buscar razón, para ver que es Dios aqueste garzón.

Dale el corazón

y yo esté empeñada, va con los Reyes

la mi manada.

Unida a la Navidad está la fiesta de la Circuncisión, que rememora la que se le practicó a Jesús a los ocho días de su nacimiento, como era preceptivo en la ley judaica. Al parecer, Santa Teresa era muy devota de esa celebración litúrgica y los villancicos que tratan este rito surgieron naturalmente del entusiasmo de la madre por tal efemérides. En ambos se resalta el dolor que sufrió el Niño por la incisión, premonición de los dolores de la Pasión, y, por tanto, se integran en el motivo del «nacer para sufrir» o «nacer para morir», ya presente en otros villancicos navideños. Lo destacable es cómo este tópico se sale del molde puramente lírico mediante la intervención y el protagonismo de los pastores, lo que confirma que muy probablemente la santa asumía la presencia pastoril y el diálogo como componentes esenciales del género villanciqueril, como venimos mostrando. En uno de los villancicos, Vertiendo está sangre, los protagonistas son Dominguillo, Brasillo y Llorente, que se lamentan por la injusticia de hacer sufrir a un inocente:

—Sí, que está muriendo

por quitar el mal.

¡Oh, qué gran zagal

será, por mi fe! 
¡Domiguillo, eh!

— ¿Tú no has mirado

que es niño inocente?

Ya me lo han contado

Brasillo y Llorente.

Este Niño viene llorando, villancico dedicado al mismo tema, se centra en un motivo específicamente navideño: el llanto del Niño, generalmente causado por el frío, el hambre, etc., y aquí por la circuncisión. Aunque la pieza mantiene en general el tono poético, termina con un breve y animado diálogo entre Gil y Pascual, a modo de exhortación al amor y al consuelo al Niño:

—Dime, Pascual, ¿qué me quieres, que tantos gritos me das?

-Que le ames, pues te quiere

y por ti está tiritando.

Mírale, Gil, que te está llamando.

El villancico de tono lírico, debido en gran parte a esa interlocución de los pastores ya bien presente a finales del siglo XVI, como se comprueba en los villancicos de la santa, fue adoptando en el ámbito religioso, y en concreto, de la liturgia, un tono dialógico que lo asienta definitivamente como «villancico barroco», «villancico parateatral» o «villancico paralitúrgico»» ${ }^{17}$, género plenamente desarrollado en el siglo XVII y extendido hasta el XVIII. Estas piezas solían imprimirse en pliegos, cuya datación más antigua es 1612, y se insertaban habitualmente en los maitines de determinadas fiestas, durante los oficios litúrgicos, sobre todo de Navidad y Reyes, llegando a fijar una estructura básica en Estribillo y Coplas, secciones que podían ir precedidas de una Introducción. Las líneas constitutivas del género fueron básicamente tres: los villancicos que conservaron el tono lírico, los parateatrales de corte literario, que enlazan directamente con los villancicos teresianos, y los de temática política o de circunstancias ${ }^{\mathbf{1 8}}$. En esta segunda parte del trabajo vamos a comentar los villancicos que se compusieron con motivo de la beatificación de Santa Teresa, en 1614, que se adscribirían a los «de circunstancias», pero que no circularon en pliegos, sino insertos en dos extensas «relaciones» que se escribieron para dejar constancia de las grandes celebraciones a

17 Esta deriva no impidió que se siguieran componiendo villancicos con predominio de lo lírico. Sin ir más lejos, Lope de Vega escribió preciosos villancicos líricos, muchos de ellos incluidos en Pastores de Belén (1612). El término «paralitúrgico» es empleado por Llergo en su libro sobre el género (Llergo 2017), precisamente para incidir en el contexto de su ejecución.

18 Para profundizar en las características generales del villancico barroco, véanse los estudios recientes de Llergo (2017), Borrego (2013: 127-128) y Borrego (2018: 58-61). 
la nueva beata ${ }^{19}$. La beatificación de Teresa de Ávila ${ }^{20}$, promulgada el 24 de abril de 1614, se celebró en 85 lugares de la península (ciudades, villas y pueblos), donde se desplegaron todo tipo de actos festivos recogidos en su mayoría en una larguísima relación, la del padre Diego de San José (1615) y, además, en ocho relaciones de fiestas celebradas en lugares concretos que aquí no detallaré. Entre la multitud de manifestaciones festivas ocuparon un lugar central los certámenes poéticos y las poesías que se recitaron en lugares sagrados, entre ellos, los conventos carmelitanos. Me han interesado dos relaciones en las que no solo se dice que «se cantaron villancicos», sino que se transcribe la letra de los mismos. En primer lugar, contamos con la relación de José Dalmau (1615), que relata las celebraciones de Barcelona, desde que se recibió la noticia hasta las propias fiestas por la beatificación, que duraron una semana y culminaron el domingo 5 de octubre. Dalmau asigna nada menos que a Lope de Vega los ocho villancicos que sirvieron para «entretener el oficio» (Dalmau 1615: ff. 38r-41v) ${ }^{21}$. Sobre esta autoría, hay quien no la pone en duda (Palacios Garoz 1995: 46); hay quien no la considera ${ }^{22}$ y hay quien la cuestiona (Lambea 1999: 32). Se cantaron en la iglesia de San José de los padres Carmelitas ${ }^{23}$, en uno de los días de la octava, donde «se pusieron

19 Esto no impide que, además de en las largas relaciones, estos villancicos (u otros con motivo de la beatificación) fueran impresos en pliegos, la forma habitual de transmisión de estas piezas, pero a día de hoy no tenemos noticia de que circularan por este cauce.

20 El Breve de beatificación de la madre Teresa, firmado por Pablo V en Roma, el 24 de abril de 1614, declaraba su condición de beata y el día 5 de octubre su fiesta. Excelentes estudios sobre estas fiestas de beatificación son los de Ignacio Arellano y Ascensión Mazuela Anguita, contenidos en Borrego y Olmedo (2017). Sobre la proyección de los escritos y la vida de la santa, véase también Borrego y Losada (2016).

21 Se incluyen, además, los seis primeros en un manuscrito conservado en la Universitat de Barcelona, con signatura ms. 1113, titulado Opúsculos espirituales de los padres José de San Francisco y Juan de Jesús María, procedente, según ficha bibliográfica, «seguramente» del convento de los carmelitas descalzos de Barcelona. Se consideran «para la beatificación de Santa Teresa». Es curioso que no se hayan copiado los dos villancicos finales, que se refieren a la rivalidad entre Alba de Tormes y Ávila, como veremos. Nuestros villancicos están entre los ff. 383r-386r.

22 Por ahora no he encontrado estas piezas en ninguna antología ni compilación de la poesía de Lope de Vega.

23 El cronista apunta que las carmelitas de Barcelona también compusieron poemas: «En la iglesia de las religiosas descalzas de la mesma orden, también se pusieron muchas tarjetas con poesías y jeroglíficos de mucho ingenio y arte, de las cuales solo he podido recoger las que se siguen». A partir de aquí se transcriben las poesías de las monjas en las mismas tarjetas, y otras composiciones: en latín, como epigramas con todas las musas (ff. 41r-46r); poemas en catalán: «cançó a la santa» (ff. 46r-47r); sextina «al Sagrat Mont del Carmelo» (ff. 47r-48r), en el que se alaba la vuelta a la regla primitiva; soneto de don Miguel de Camos «a la devoción» (f. 48v); canción «a la devoción» (ff. 49r-50r); décimas «a les figues que per manament de son confesor sehuia a Cristo noster señor la mare Teresa de Iesús» (ff. 50r-52r), esta última de índole burlesca. 
muy lindas tarjetas, en las cuales estaban escritas poesías de mucha arte en lengua latina y castellana, de las cuales he procurado escoger las mejores y ponerlas en este libro» (Dalmau 1615: f. 21r). Hubo numerosos poemas previos a los villanci$\cos ^{24}$, a los que se alude al final de la celebración:

Para cantar la Capilla, mientras se entretenían los oficios, también hubo muy curiosos villancicos y seguidillas, los más dellos compuestos por el ingenioso poeta Lope de Vega. Y porque sé que han de ser de gusto, me ha parecido continuarlos con la historia (Dalmau 1615: f. 38r).

Sin embargo, hay que decir que la mayoría pierden el genuino componente popular, tan marcado en las piezas de la abulense, y se convierten en villancicos de «circunstancias», centrados en la vida de la santa o en aspectos de su mística. En el primero se alude al hábito carmelitano y al pesar del demonio por la santidad de Teresa, y se relacionan los colores del hábito con dos virtudes: lo blanco con la castidad y lo pardo con el sacrificio, o lo que es lo mismo, los trabajos que pasó la recién beatificada. La última estrofa alude a un motivo repetido en la beatificación: su condición de virgen y madre (espiritual) de tantos hijos. El villancico adquiere un cariz narrativo, a modo de «hagiografía», pues se relatan los rasgos sobresalientes de su vida:

\section{Vistiose una vez Teresa \\ de pardo y blanco sayal, no le va de amores mal, pues al demonio le pesa.}

Teresa, con pensamiento de ser esposa de Dios, de aquestos colores dos hizo galas a su intento:

24 Aporto una breve noticia sobre estos poemas para dar una idea de las variadas formas métricas que se emplearon en alabanza de la santa de Ávila. Además de epigramas latinos, se compusieron dos sonetos: uno, dedicado a "cuando vio un serafín con un dardo que la hirió el corazón» (f. 24v); otro, «al tránsito de la Madre Santa Teresa de Jesús, cuando abiertos los cielos salió su alma en figura de paloma blanquísima» (f. 25r); dos canciones: la primera, «al deseo que tuvo nuestra madre Santa de morir o padecer» (ff. 25r-26v), y la segunda, «A la bienaventurada Santa Teresa de Jesús en su beatificación» (ff. 26v-28r), en la que resume su vida; varios jeroglíficos (ff. 28r-33r); un romance, en el que se cita la transverberación y la excelsitud de Dios, «iAy Dios, qué exceso / que andéis de una mujer de amores preso / y que ella herida / por vuestro amor se pierda, y gane vida!» (ff. 33r-34r); en los ff. 34r-36v se recogen los epigramas y jeroglíficos que envió el padre Pablo Mascarel; finaliza este despliegue de poemas con otro romance «de nuestra madre santa» (ff. 36r-37v), en torno a la figura bíblica del cedro, para pasar luego a recorrer su vida hasta su muerte en Alba. 
lo blanco fue casta empresa, lo pardo, al trabajo igual. No le va de amores mal, pues al demonio le pesa.

Pesole por ver que habían de nacer de aquesta boda hijos que la tierra toda con su luz ilustrarían, $\mathrm{y}$, aunque ser virgen profesa, es su madre celestial, no le va de amores mal, pues al demonio le pesa.

El segundo alude a un motivo propio del Cantar de los Cantares, libro sobre el que meditó largamente la santa y sobre el que escribió algunos comentarios ${ }^{25}$. el esposo que abre la puerta a la amada, que espera «descalza» a la puerta de su cabaña tras una penosa búsqueda:

Cuando el Esposo despierta
mucho a su Teresa ensalza,
que con hallarla descalza
le abrió tan presto la puerta.
Cuando el Esposo divino
su Teresa despertó,
aunque descalza la halló
a verle corriendo vino.
Él, viéndola tan despierta,
por mayor virtud ensalza,
que con hallarla descalza
le abrió tan presto la puerta.

No enfrena el paso amoroso tener lavados los pies, que llegó como Moisés a la zarza de su Esposo.

25 Teresa manifiesta en más de una ocasión el refugio y consuelo que le proporciona este libro bíblico, hasta el punto de que decide glosarlo para las monjas de sus carmelos. Tras someterlo a la aprobación a dos teólogos, uno de ellos, el dominico Diego de Yanguas lo reprueba por no parecerle adecuado que una mujer escribiese sobre la Escritura. Tras oír su parecer, la santa quema el libro original. Aunque Domingo Yáñez, el otro informante, lo aprueba, apenas se pudo salvar la copia de una pequeña parte. 
Está con la luz despierta

y él, prudente, la ensalza, que con hallarla descalza

le abrió tan presto la puerta.

Otro de los motivos frecuentes en la hagiografía teresiana es su maternidad espiritual, aquí enfocada hacia la pobreza dada su numerosísima «descendencia», por lo que a sus múltiples hijos les hace falta un padre, que no es otro que Dios:

Es de tantos hijos madre

Teresa, que no hay pensar de poderlos sustentar

si Dios no fuera su padre.

Tantos hijos le han nacido

a la divina Teresa

de aquella dichosa empresa

que de ser madre ha tenido,

que con ser tan buena madre

medio no pudiera hallar

de poderlos sustentar

si Dios no fuera su padre.

Desconfiada del suelo,

siempre corto de favor,

dioles el padre mejor

que hay en la tierra y el suelo,

que no hallarán, siendo madre,

modo, traza ni lugar

de poderlos sustentar

si Dios no fuera su padre.

En el siguiente villancico se alude a «Teresas» que han sido reinas, sin dar pista de ninguna en concreto. Podría tratarse de Teresa de Portugal (1175-1250), cuyo matrimonio finalmente anulado con Alfonso IX de León (primo hermano) la abocó al claustro hasta su muerte, siendo beatificada por el papa Clemente XI en 1705. O de Teresa de León (¿1080?-1130), infanta de León y condesa de Portugal (hija ilegítima de Alfonso VI de León), que gobernó el condado de Portugal durante la minoría de edad de su hijo con el título de reina. Pero ninguna iguala a la carmelita abulense, que reina en el cielo por su santidad:

Teresas, reinas del suelo, hubo muchas, pero vos, 
después que reináis en Dios

pasastes el nombre al cielo.

Un nombre tan excelente no sin causa os le darían, pues Teresas ser solían las reinas antiguamente. Dieron a su patrio suelo gloria y honor, pero vos después que reináis en Dios pasastes el nombre al cielo.

Pues quien a Dios sirve reina, reino en la tierra tuvistes, y en el siglo también fuiste, por vuestras virtudes, reina. Ya las Teresas del suelo se honrarán con vos, pues vos, después que reináis en Dios pasastes el nombre al cielo.

Los villancicos de «enigma», de amplia difusión en la época, se planteaban a modo de diálogo, recuperando así en este caso al zagal como interlocutor. El enigma de este quinto villancico consiste en conjugar la condición de virgen y madre en Santa Teresa, atreviéndose de este modo a equipararla a la mismísima Virgen María.

¿Qué es cosa, y cosa tan bella mas que no la sabéis vos?

Que después de la de Dios hay una madre doncella.

Es un enigma divino, zagal, y una cosa y cosa, más nüeva y misteriosa que la del rey y del vino. No la vio Tebas tan bella ni oímos jamás los dos que después de la de Dios hay una madre doncella.

Teresa, virgen prudente, tantos hijos engendró que el nombre se le quedó 
de madre por excelente.

Con esto, y saber que es ella, tendréis por posible vos

que después de la de Dios

hay una madre doncella.

Su condición de alma enamorada de Dios se ve corroborada en los versos del sexto villancico, en los que se ensalza el «grado de amor» ${ }^{26}$ que alcanza Santa Teresa, aludiendo indirectamente a su condición de escritora espiritual y de doctora de la Iglesia que, lamentablemente, tardaría más de tres siglos en reconocerse:

Hoy de amor el grado

dan a Teresa,

por primera divina

de sus licencias.

El dotor soberano

de amor divino,

que tan sabio procede

de Padre e Hijo,

graduar ha querido

su amada esposa,

y la escuela toda

su grado aprueba

por primera divina

de sus licencias.

Su esposo le ha dado

licencias tantas

que en el modo que puede

con él se iguala:

tan enamorada

que a sus requiebros

responden los cielos

«Victor, Teresa»,

26 No es la primera vez que Lope identifica al amor como un «maestro» que enseña al enamorado e ilumina su entendimiento, acorde con la visión neoplatónica que caracteriza muchos de los discursos amorosos de sus comedias. Baste a modo de ejemplo recordar algunos versos de $L a$ dama boba, compuestos en 1613, fecha cercana a la de estas fiestas, en los que Finea se ha «graduado» gracias al amor: «Ya puedes del grado honrarme, / dándome a Laurencio, amor, / con quien pudiste mejor, / enamorada, enseñarme. [...] ¡Gran fuerza tiene el amor, / catredático divino!» (Vega 1976: 144-145). 


\section{por primera divina \\ de sus licencias.}

El séptimo villancico nos traslada la rivalidad entre Ávila y Alba de Tormes, cuyos puntos de fricción comienzan desde la muerte de la santa en Alba, con las disputas sobre qué localidad era más merecedora de conservar su cuerpo, hasta el punto de sufrir varios traslados que ahora no viene al caso comentar. El villancico se centra precisamente en esa disputa: Ávila es el oriente porque allí nació Teresa, pero Alba no merece menos al ser el ocaso, porque allí murió:

Son del cielo (con celos)

Ávila y Alba, el oriente y el ocaso del sol de España.

Cuando mira el cielo un sol en la tierra que su gloria encierra, quisiera ser suelo lleno de recelo. Mira los dos polos en los cuales solos el mundo abarca el oriente y el ocaso, Ávila y Alba, el oriente y el ocaso del sol de España.

La una gloria quiere porque allí el sol nace; la otra, pues renace cuando allí el sol muere. Cada cual prefiere con igual victoria su ventura y gloria, que al fin son ambas el oriente y ocaso del sol de España, Ávila y Alba, el oriente y el ocaso del sol de España.

Sin embargo, el último poema parece confirmar la inclinación a Alba de Tormes, pues todo él es un puro elogio a la villa salmantina, lo que refuerza la autoría 
de Lope, pues, como es sabido, el Fénix vivió allí al servicio del V Duque de Alba, don Antonio Álvarez de Toledo, entre 1591 y 1595, fechas cercanas a la muerte de la santa y en las que la Casa de Alba se empleó a fondo en la promoción de la vida, la santidad y los escritos teresianos ${ }^{27}$. Lope procede a exaltarla mediante juegos de palabras con el alba como figura de la muerte que al fin y al cabo es vida, como símbolo del amanecer a una vida divina y nueva:

Ya el sol de Teresa en Alba muestra su claro arrebol, que las campanitas de Alba dicen que ha salido el sol.

El sol, que en Alba se puso donde un alba fue su ocaso, pues salió en el cielo al paso que en el cielo se traspuso, haciéndole hoy Alba salva vuelve a esparcir su arrebol, que las campanitas de Alba dicen que ha salido el sol.

Púsose en Alba y dejola hecha de alba, noche escura, mas hoy de noche, alba pura, la torna a hacer y arrebola. Ya amanece y su luz, Alba, alegra el cielo español, que las campanitas de Alba dicen que ha salido el sol.

Tras la luz de su memoria, que era la luna en su ausencia vino del sol la presencia que fue la luz de su gloria. Sale hoy su pureza salva cual el oro del crisol, que las campanitas de Alba dicen que ha salido el sol.

\footnotetext{
27 Don Fernando Álvarez de Toledo, gran duque de Alba, fallecido el mismo año que la santa, 1582 , fue gran amigo suyo y dejó en testamento 14.000 ducados para seguir la causa de Teresa en Roma, por la común opinión de la santidad de Teresa de Jesús. Los duques de Alba, ya desde tiempos de Teresa, mostraron una gran cercanía y devoción a la santa, y serán los que promuevan su beatificación, canonización y su reconocimiento como patrona de España.
} 
Conocemos tan solo la letra de tres villancicos más, cuyo autor, Luis Díaz de Aux, escribe la relación de las fiestas de la beatificación en Zaragoza (Díaz de Aux 1615: 51-52), en la que se incluyen. Sabemos que el 4 de octubre, víspera de la fiesta principal, se interpretó el oficio divino por las capillas de música de La Seo y la Basílica del Pilar, hubo danzas, música instrumental, canto de villancicos y de motetes en varios conventos y palacios, entre ellos el de los carmelitas, pero desconocemos la letra. El día de la fiesta, 5 de octubre, hubo canto del Oficio Divino y misa mayor por la capilla de música de La Seo, procesión con música instrumental y canto de «motetes y villancicos» (44), de los que, afortunadamente, sí se refiere la letra. El entorno fue solemne, en contraposición a las celebraciones de los siguientes días, donde hubo una «fiesta y paseo de los estudiantes», con «grande número de gente con muchos vistosos y varios disfraces, extraordinarias y graciosas invenciones» (52), otra de labradores (58), certámenes poéticos, muchos de ellos de cariz jocoso, juegos burlescos con música instrumental y danza, y hasta una comedia en la que «hubo apacible música, discretas letras cantadas con destreza y peregrinos tonos» (147). De los tres villancicos conservados, destaco el primero, en el que un pastor exhorta a otro, Gil, a vestirse para ver el prodigio de las bodas entre la «zagala del Carmelo» y Cristo:

Vístete, Gil, date priesa, las campanas te provocan, que repican y tañen y tocan a las bodas de Teresa.

¡Dan, din, don, que la novia es bella, pues le da parabienes toda la aldea!

Hoy verás lo que no has visto, pues con aplauso del cielo, la zagala del Carmelo se ha desposado con Cristo. Toma el grabán $[s i c]^{28}$, date priesa, que hasta las torres provocan, que repican y tañen y tocan a las bodas de Teresa.

¡Dan, din, don, que la novia es bella, pues le da parabienes toda la aldea!

Elías, aquel del cielo, viendo levantar su honor

\footnotetext{
28 Entendemos 'gabán' como «Cierto género de capote con capilla y mangas, hecho de paño grueso y basto, de que usa ordinariamente la gente del campo para defenderse de las inclemencias del tiempo» (Autoridades).
} 
como si fuera el Tabor, ha de venir al Carmelo.

Lleva el zurrón, date priesa, pues tañendo nos provocan, que repican y tañen y tocan a las bodas de Teresa.

¡Dan, din, don, que la novia es bella, pues le da parabienes toda la aldea!

El segundo y el tercero son villancicos de carácter circunstancial: se juega con los consabidos tópicos y dobles sentidos del alba y el sol, y se alaba la reforma del Carmelo. Nótese de nuevo la prioridad que se otorga a Alba de Tormes en el segundo:

\section{El alba del Carmen en Alba de Tormes, con el alba sale, con el sol se pone.}

Cuando al sol del suelo el alba hace salva, del Carmen al alba la hace al sol del cielo: y corriendo el velo de un sol puesto en cruz, porque con su luz su luz perficione, con el alba sale, con el sol se pone.

Con nuevas señales sus hijas la han visto por el sol de Cristo derramar cristales; tantas son y tales las perlas que vierte, para que en su muerte Dios las galardone, con el alba sale, con el sol se pone.

La reforma del Carmelo emprendida por Santa Teresa ve su reconocimiento en el último villancico: 
Teresa, si en vos se ve restaurado lo perdido, no para mal del Carmelo ha sido, mas para bien del Carmelo fue.

Vuestra rara perfección pudo tanto con el cielo que ha restaurado al Carmelo el bien de su religión.

Y pues sois causa que esté en estado tan subido, no para mal del Carmelo ha sido, mas para bien del Carmelo fue.

¿Qué más bien pudo alcanzar mirando vuestra aspereza, pues por ella a tal alteza de gloria pudo llegar? Y si el fervor se le ve que en su principio ha tenido, no para mal del Carmelo ha sido, mas para bien del Carmelo fue.

Tras las fiestas de beatificación vinieron las de canonización en 1622, y durante los años sucesivos se escribieron villancicos y poemas para Santa Teresa, que merecerían un estudio más amplio y detallado. Ahora, para cerrar este siglo de villancicos, entre las primeras composiciones de la santa, que suponemos de los años $60^{29}$, y las posteriores dedicadas a ella, deseo dar breve noticia de un raro pliego de siete hojas sin paginar, conservado en la Biblioteca Nacional de España, justo de 1661, que conserva tan solo dos villancicos ${ }^{30}$. Estas piezas, que ya constan explícitamente de estribillo y coplas (o letras) y de las que se indica la autoría («Por el Reverendo Padre Maestro Prior de dicha Congregación») se cantan en el entorno de una fiesta conventual carmelitana, en concreto en Valencia, para celebrar algo tan ajeno a la clausura como el nacimiento del futuro Carlos II en noviembre de 1661 y el segundo aniversario de la boda de su hermanastra

29 La cronología de la poesía de Santa Teresa es otro tema de difícil acometimiento que necesitaría una pronta clarificación. No es tarea fácil dado el carácter oral de muchas de estas composiciones y, como decíamos al principio, dado el descuido en su escritura y conservación. He determinado el año 1562, que figura en el título, por ser el primero del que se sabe con seguridad que estaba escribiendo, en concreto el Libro de la Vida. Podemos suponer que por estas fechas comenzaría a escribir también algunos de sus poemas.

30 En la década de los 60 del siglo XVII lo habitual era que los pliegos de villancicos contuvieran entre 8 y 10 piezas. 
M. ${ }^{a}$ Teresa, quien había contraído nupcias con Luis XIV en 1659, como fruto de la Paz de los Pirineos. En el primer villancico se retoma lo político y se exulta por el nacimiento del heredero, que se encomienda directamente a la santa:

\author{
Dilación dichosa \\ la desta fiesta, \\ pues parece esperaba \\ solo esta nueva \\ de que príncipe gozan \\ el Rey y Reina, \\ ¡vivan, vivan, mil años \\ reinar les vean! \\ $[\ldots]$ \\ El Príncipe, Madre, es tuyo, \\ por tu cuenta desde hoy corre, \\ empeño es tuyo, Teresa, \\ de que el Príncipe se logre ${ }^{31}$
}

(Anónimo ¿1661?: 1-3)

El segundo villancico «celebra la gracia natural y sobrenatural que tuvo N. S. con los que la comunicaban, para ganar sus corazones y llevarlos a N. Señor» (Anónimo i1661?: 4). Lo curioso de esta pieza es que se glosa uno de sus más famosos poemas místicos, que aparece impreso en disposición vertical en el margen de la séptima y última hoja («Aquella ${ }^{32}$ divina prisión / del amor en que yo vivo / hace a Dios mi cautivo / y libre mi corazón»). Al hilo de la figura del oro (Cristo) atraído por el imán (Teresa), se invierte la imagen del alma atraída por la divinidad, llegando a ser la santa el objeto de amor de todo un Dios. Pero a su vez se alude a Teresa de Austria, que ha atraído la voluntad y el afecto de su marido, el rey de Francia:
Del imán, del imán
de las dos Teresas, su afecto ha atraído, aunque en Roma queda, a celebrar viene aquesta real fiesta.

(Anónimo ¿1661?: 5)

\footnotetext{
31 Recordemos que Felipe IV había tenido cuatro hijos varones antes, dos con Isabel de Borbón y otros dos con Mariana de Austria, y que todos habían fallecido: Baltasar Carlos, en 1646, con solo 16 años; Francisco Fernando, en 1634, con 8 meses; Felipe Próspero, en 1661 con apenas 4 años; y Fernando Tomás, en 1659, que no llegó al año. En las citas del pliego la paginación es mía.

32 El determinante demostrativo de la poesía original es «Esta», no «Aquella».
} 
Los dos años de matrimonio que celebra la infanta se comparan con un lapso temporal similar de visiones y experiencias místicas de la santa:
Dos años tu esposo viste continuos junto a ti misma, qué mucho si tú el imán fuiste, y oro su cabeza. Fuiste al fin tan atractiva que fue prisión y cadena tu amor de ese oro más fino, como cantas en tu letra.

$$
\text { (Anónimo ¿1661?: 6-7) }
$$

Sin embargo, no podía faltar una alusión especial a la condición de fundadora de Santa Teresa, rompiendo en cierto modo la dualidad del villancico:

$$
\begin{aligned}
& \text { Bien claro lo está diciendo } \\
& \text { tu ilustre y heroica empresa } \\
& \text { de Descalzas y Descalzos } \\
& \text { que diste, Madre, a la Iglesia. }
\end{aligned}
$$

(Anónimo ¿1661?: 6)

Basten, pues, estas muestras, que abarcan prácticamente un siglo, con tres hitos temporales concretos (1562-1582, 1614 y 1661), para comprobar cómo el villancico — en este estudio, de Teresa o «para Teresa»-, fue una forma proteica, polivalente, capaz de acoger diversos temas y diferentes tonos, desde los cómicos diálogos de pastores hasta los motivos más místicos, pasando, cómo no, por preocupaciones políticas y regias como la pérdida de los sucesivos herederos. Una vez más, la huella de Santa Teresa no deja indiferente y los tópicos teresianos penetran en las diversas formas y temas del villancico. 


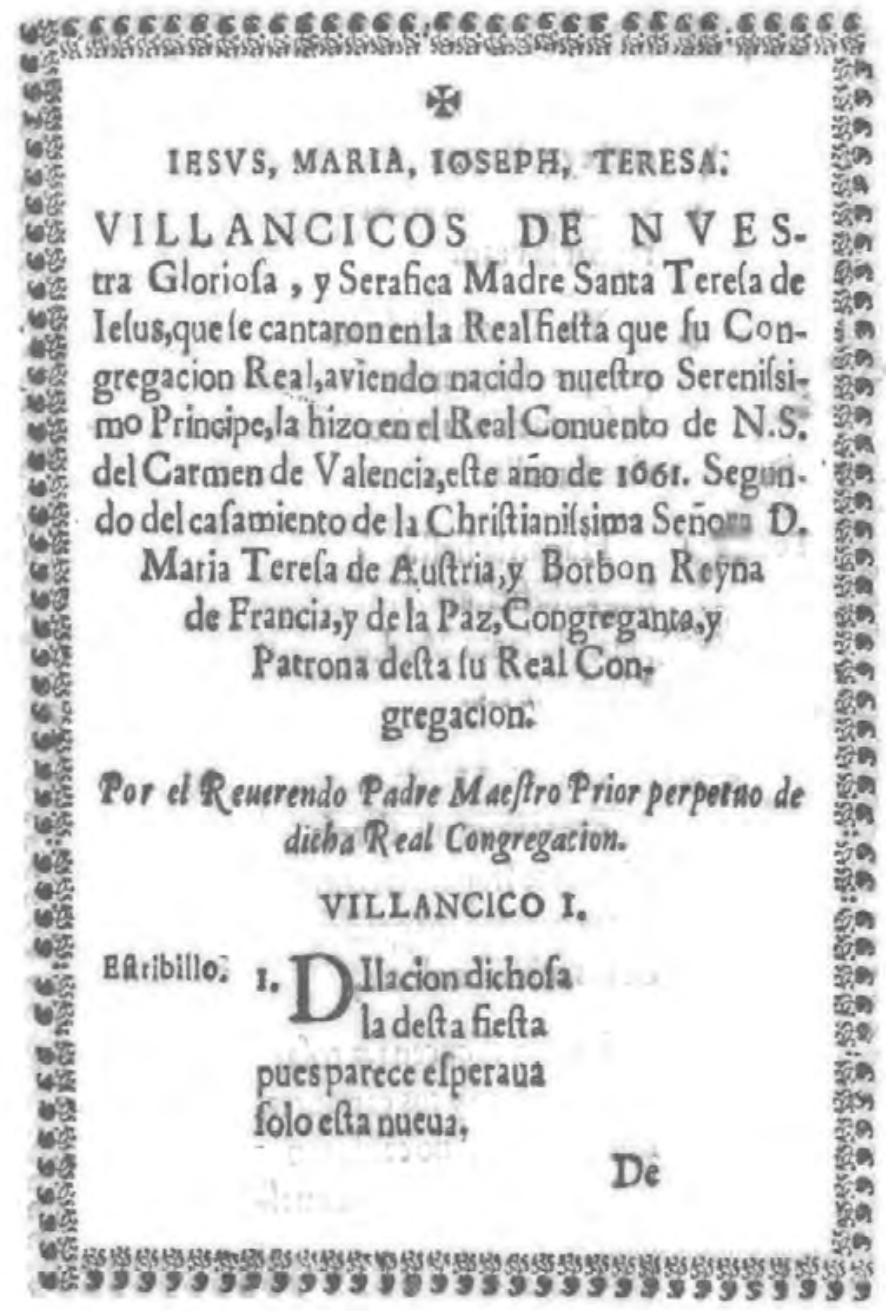

- Bibliotoca Nacional do Espafa ¿Valencia?: [s.e.] [BNE, VE/124/22]. 


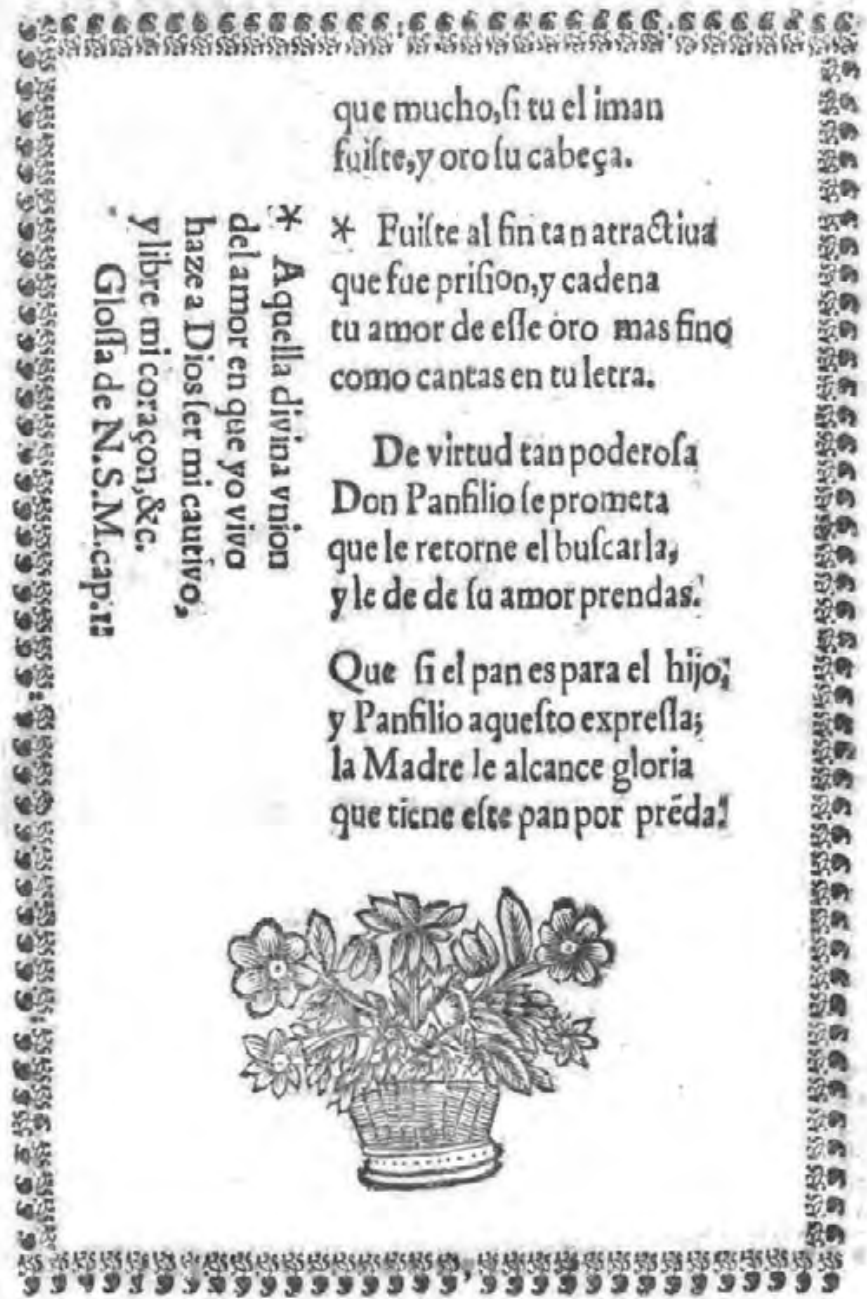

O Biblioteca Nacional de España

Anónimo (¿1661?). Villancicos de nuestra gloriosa y seráfica madre Santa Teresa de Jesús [...]. ¿Valencia?: [s.e.], p. 7 [BNE, VE/124/22]. 


\section{BIBLIOGRAFÍA}

\section{Fuentes PRIMARIAS}

Anónimo (¿1661?). Villancicos de nuestra gloriosa y seráfica madre Santa Teresa de Jesús, que se cantaron en la real fiesta que su congregación real, habiendo nacido nuestro serenísimo príncipe, la hizo en el Real Convento de N. S. del Carmen de Valencia, este año de 1661. Segundo del casamiento de la cristianísima señora D. María Teresa de Austria y Borbón, Reina de Francia y de la Paz, congreganta y patrona desta su real congregación, por el Reverendo Padre Maestro Prior Perpetuo desta congregación. ¿Valencia?: [s.e.] [BNE, VE/124/22].

Dalmau, José (1615). Relación de la solemnidad con que se han celebrado en la ciudad de Barcelona las fiestas a la beatificación de la Madre S. Teresa de Iesús. Barcelona: Sebastián Matevad [BNE, 2/34064].

Diego de SAN José (1615). Compendio de las solenes fiestas que en toda España se hicieron en la Beatificación de N. S. M. Teresa de Jesús [....]. Madrid: Viuda de Alonso Martín [BNE, 2/46369].

DíEz DE Aux, Luis (1615). Retrato que a la beatificación de Santa Teresa de Jesús [...] hizo [...] la [...] ciudad de Zaragoza. Zaragoza: Juan de la Naja y Quintanar [BNE, R/457].

MARÍA DE SAN José (1913). Libro de recreaciones, ramilletes de mirra, avisos, máximas y poesias [1585]. Padre Silverio de Santa Teresa (ed.). Burgos: Monte Carmelo [BNE, ms. 2176].

Ribera, Francisco de, S.I. (1590). La vida de la Madre Teresa de Jesús [...]. Salamanca: Pedro Lasso [BNE, R/ 29512].

Santa Teresa de Jesús (1861). «Poesías». En Vicente de la Fuente (ed.), Escritos de Santa Teresa. Madrid: Rivadeneyra, BAE, 53, pp. 501-518.

Santa Teresa de Jesús (1922). «Poesías». En Silverio de Santa Teresa, O. C. D. (ed.), Obras de Santa Teresa de Jesús. Burgos: Monte Carmelo, pp. 77-119.

Santa Teresa de Jesús (1972). «Poesías». En Ángel Custodio Vega, O. S. A. (ed.), La poesía de Santa Teresa. Madrid: BAC, pp. 239-277.

Santa Teresa de Jesús (1977). «Poesías». En Alberto Barrientos y José Vicente Rodríguez (eds.), Lira mística. Madrid: Editorial de Espiritualidad, pp. 25-67.

Santa Teresa de Jesús (1997). «Poesías». En Maximiliano Herráez (eds.), Obras completas [de Santa Teresa]. Madrid: Sígueme, pp. 1103-1140.

Santa Teresa de Jesús (2000). «Poesías». En Enrique Llamas et alii (eds.), Obras completas [de Santa Teresa]. Madrid: Editorial de Espiritualidad, [1. ${ }^{\circ}$ ed. 1963] ${ }^{33}$, pp. 1158-1189.

33 La editorial fue la de Espiritualidad, pero en la primera edición el editor fue el padre Isidoro de San José. 
Santa Teresa de Jesús (2013). «Poesías». En Efrén de la Madre de Dios y Otger Steggink, O. C. D. (eds.), Santa Teresa de Jesús. Obras completas. Madrid: BAC, [1. ${ }^{\mathrm{a}}$ ed. 1954], pp. 509-518.

Vega, Félix Lope de (1976). La dama boba. Diego Marín (ed.). Madrid: Cátedra.

VV. AA. (1982). Libro de romances y coplas del Carmelo de Valladolid. Víctor García de la Concha y Ana M. á Álvarez Pellitero (eds.). Salamanca: Consejo General de Castilla y León, 2 vols.

VV. AA. (entre 1651-1700). Opúsculos espirituales de los padres José de San Francisco y Juan de Jesús María, letra del siglo XvII. [s.1.]: [s.e.], 422 ff. [Biblioteca de la Universidad de Barcelona: ms. 1113].

\section{BIBLIOGRAFÍA CRÍTICA}

Arellano, Ignacio (2017). «Santa Teresa, protagonista teatral en el Siglo de Oro». En Esther Borrego y Jaime Olmedo (dirs.), Santa Teresa o la llama permanente. Estudios históricos, artísticos y literarios en el $V$ centenario del nacimiento de la Santa (1515-2015). Madrid: Centro de Estudios Europa Hispánica, pp. 195-220.

Benito DE LuCAs, Joaquín (2015). La poesía de Santa Teresa: entre la tradición y lo divino. Madrid: RIALP.

Borrego Gutiérrez, Esther (2013). «Un siglo de impresión de pliegos de villancicos. El caso de los Monasterios Reales de la Encarnación y las Descalzas (16491752)». El libro de poesía entre Barroco y Neoclasicismo (1651-1750) (volumen monográfico). Criticón, 119, pp. 127-143.

Borrego Gutiérrez, Esther y José Manuel Losada (dirs.) (2016). Cinco siglos de Teresa. La proyección de la vida y los escritos de Santa Teresa de Jesús. Madrid: Fundación M. ${ }^{\text {a }}$ Cristina Masaveu Peterson.

Borrego Gutiérrez, Esther y Jaime Olmedo (dirs.) (2017). Santa Teresa o la llama permanente. Estudios históricos, artísticos y literarios en el V centenario del nacimiento de la Santa (1515-2015). Madrid: Centro de Estudios Europa Hispánica.

Borrego Gutiérrez, Esther y Javier Marín (eds.) (2018). El villancico en la encrucijada. Nuevas perspectivas en torno a un género literario-musical (ss. XV-XIX). Kassel: Reichenberger.

Custodio Vega, Ángel, O. S. A. (1972). La poesía de Santa Teresa. Madrid: BAC.

Lambea, Mariano (1999). Los villancicos de Joan Pau Pujol (1570-1626). Contribución al estudio del villancico en Catalunya en el primer tercio del XVII. Barcelona: Universidad Autónoma de Barcelona.

Llergo Ojalvo, Eva (2017). El villancico paralitúrgico: un género en su contexto. Santander: Real Sociedad Menéndez Pelayo.

Mazuela Anguita, Ascensión (2017). «Música y paisaje sonoro en las fiestas de beatificación de Santa Teresa en 1614». En Esther Borrego y Jaime Olmedo (dirs.), Santa Teresa o la llama permanente. Estudios históricos, artísticos y literarios 
en el $V$ centenario del nacimiento de la Santa (1515-2015). Madrid: Centro de Estudios Europa Hispánica, pp. 109-126.

Palacios Garoz, José Luis (1995). El último villancico barroco en Valencia. Castelló de la Plana: Universitat Jaume I.

Recibido: 07/06/2018

Aceptado: 01/08/2018 
Villancicos de Teresa, villancicos para Teresa. De 1562 a 1661

RESUmEN: Se conservan apenas siete villancicos de Santa Teresa, protagonizados por pastores y de marcado carácter dialógico y, en cierto modo, parateatral. A su muerte, y con motivo de las fiestas de su beatificación en 1614 se escribieron multitud de poemas que celebraban su vida y virtudes, entre ellos diez villancicos de alabanza a su persona y a sus obras. Durante el siglo XVII se siguen componiendo poemas, obras de teatro y otros tipos de textos. Muestra de ello es un raro pliego de 1661 que contiene dos villancicos peculiares que aúnan la alabanza a la santa de Ávila y a miembros de la familia real, entre ellos el recién nacido Carlos II, cuya vida se encomienda a Teresa en un intento desesperado por mantener la dinastía. Con este recorrido queremos mostrar la condición proteica de un género capaz de albergar diferentes temas y enfoques.

Palabras Clave: poesía de santa Teresa, villancico, villancico paralitúrgico, pliegos.

\section{TERESA'S VILLANCICOS, VILLANCIDOS FOR TERESA. FROM 1562 TO 1661}

ABSTRACT: Only seven villancicos of Santa Teresa are conserved, carried out by shepherds and of marked dialogical character and, in a certain way, paratheatral. At his death, and because of the celebrations of his beatification in 1614, many poems were written that celebrated his life and virtues, among them ten villancicos of praise to his person and his works. During the seventeenth century poems, plays and other types of texts continue to be written. Proof of this is a rare chapbook of 1661 containing two peculiar villancicos that join the praise of the Saint of Avila and members of the royal family, including the newborn Carlos II, whose life is entrusted to Teresa in a desperate attempt to maintain the dinasty. With this journey we want to show the protean condition of a genre capable of hosting different themes and approaches.

KEYWORDS: poetry of santa Teresa, villancico, Paraliturgical villancico, Chapbooks. 


\section{Edad de Oro. Revista de Filología Hispánica}

ISSN: 0212-0429 - ISSNe: 2605-3314 <https://revistas.uam.es/edadoro/index>

Edad de Oro es uno de los máximos referentes en el área de investigación en Filología Hispánica, especialmente de los siglos XVI y XVII. Goza de un amplio reconocimiento en el ámbito académico internacional. Desde 1982 publica ininterrumpidamente, con una periodicidad anual, colaboraciones científicas de los principales especialistas de diversos centros nacionales y extranjeros. Con un público compuesto esencialmente por investigadores y expertos de todo el mundo, se dirige a cualquier persona interesada en las nuevas corrientes de los estudios humanísticos de su campo.

Dirección:

María Jesús Zamora Calvo

(Univ. Autónoma de Madrid)

Subdirección:

José Antonio Llera Ruiz

(Univ. Autónoma de Madrid)

Secretaría:

Raquel Arias Careaga

(Univ. Autónoma de Madrid)

Consejo de redacción:

Cecilia López-Ridaura

(ENES. Morelia / Univ. Nacional

Autónoma de México)

José Luis Ocasar Ariza

(Univ. Autónoma de Madrid)

Rocío Pérez Gironda

(Univ. Autónoma de Madrid)

Carolina Fernández Cordero

(Iberoamericana-Vervuert)

Admisión de originales:

María Jesús Zamora Calvo

Edad de Oro

Universidad Autónoma de Madrid

Facultad de Filosofía y Letras

Departamento de Filología Española

Campus Cantoblanco

28049 Madrid (España)

Tfno. (+34) 914976886

Correo-e: mariajesus.zamora@uam.es

Distribución, suscripción y venta:

Servicio de Publicaciones de la UAM

Universidad Autónoma de Madrid

28049 Madrid (España)
Intercambio de publicaciones:

Biblioteca de Humanidades

Universidad Autónoma de Madrid

28049 Madrid (España)

Comité científico:

Carlos Alvar (Université de Gèneve)

Ignacio Arellano (Univ. de Navarra)

Alberto Blecua

(Univ. Autónoma de Barcelona)

Jean Canavaggio

(Université Paris Nanterre)

Aurora Egido (Univ. de Zaragoza)

Víctor García de la Concha (RAE)

Luciano García Lorenzo (CSIC)

Joaquín González Cuenca

(Univ. de Castilla la Mancha)

Agustín de la Granja López

(Univ. de Granada)

Begoña López Bueno (Univ. de Sevilla)

Michel Moner

(Universitè Toulouse - Jean Jaurès)

Joan Oleza (Univ. de Valencia)

Alfonso Rey

(Univ. de Santiago de Compostela)

Lina Rodríguez Cacho

(Univ. de Salamanca)

Leonardo Romero Tobar

(Univ. de Zaragoza)

Aldo Ruffinatto

(Università degli Studi di Torino)

Lía Schwartz

(City University of New York)

Han colaborado en este volumen:

Departamento de Filología Española

(UAM)

Facultad de Filosofía y Letras (UAM)

Edad de Oro se recoge en las siguientes bases de datos y directorios: DICE; HLAS; MLA International Bibliography; PIO; ISOC-CSIC; DIALNET; SUMARIS CBUC; ULRICH'S.

Se encuentra evaluada en: SCOPUS: Q2; SCImago: SJR 2017 0.11, H Index 4; ERIH Plus: category A; CIRC: categoría C; RESH: 0.162; MIAR: ICDS 2017 10.0; CARHUS Plus+: C; LATINDEX. 


\section{EDAD DE ORO}

Revista de Filología Hispánica XXXVII

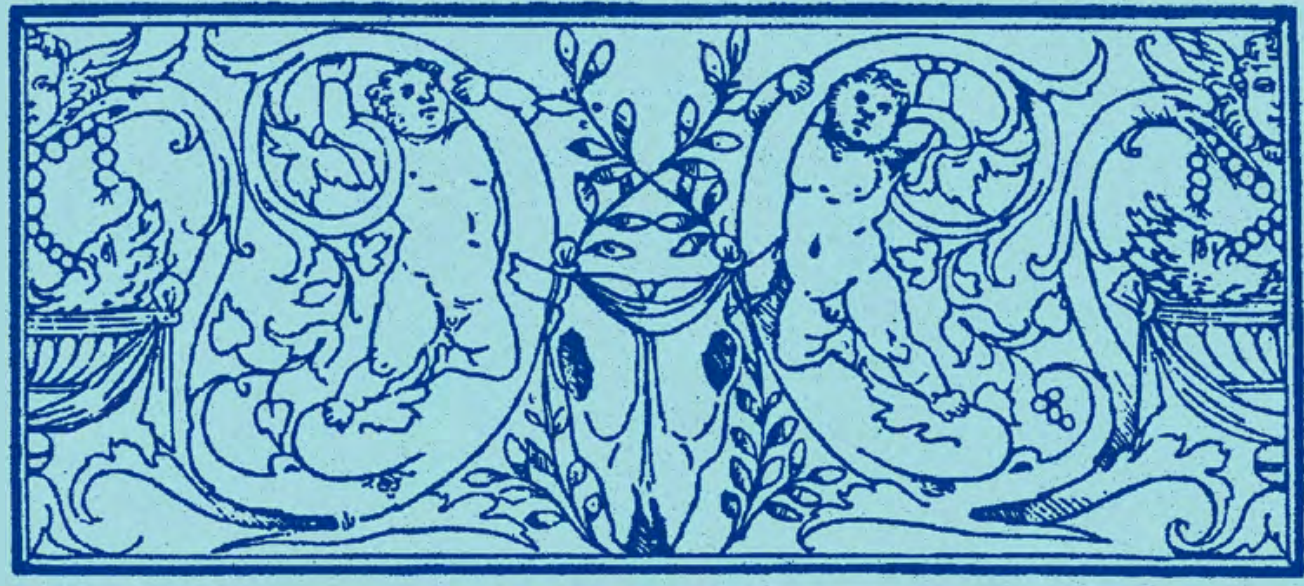

\section{DEPARTAMENTO DE FILOLOGÍA ESPAÑOLA}

EDICIONES DE LA UNIVERSIDAD AUTÓNOMA DE MADRID 